\title{
Article \\ Study on the Synergistic Effects between Petroleum Sulfonate and a Nonionic-Anionic Surfactant for Enhanced Oil Recovery
}

\author{
Huoxin Luan ${ }^{1}$, Zhaohui Zhou ${ }^{2}$, Chongjun Xu ${ }^{1}$, Lei Bai ${ }^{1}$, Xiaoguang Wang ${ }^{3}$, Lu Han ${ }^{2}$, Qun Zhang ${ }^{2}$ and Gen Li $^{4, *}$ \\ 1 Xinjiang Oilfield Research Institute of Experiment \& Testing, Karamay 834000, China; \\ luanhuoxin@petrochina.com.cn (H.L.); xcjun@petrochina.com.cn (C.X.); bailei@petrochina.com.cn (L.B.) \\ 2 State Key Laboratory of Enhanced Oil Recovery, PetroChina Research Institute of Petroleum Exploration \& \\ Development, Beijing 100083, China; zhouzhaohui@petrochina.com.cn (Z.Z.); \\ hanlu1991@petrochina.com.cn (L.H.); zhangqun1980@petrochina.com.cn (Q.Z.) \\ 3 Xinjiang Oilfield Research Institute of Exploration \& Development, Karamay 834000, China; \\ wxguang@petrochina.com.cn \\ 4 Department of Petroleum Engineering, Northeast Petroleum University, Daqing 163318, China \\ * Correspondence: lg116053717@sina.com
}

Citation: Luan, H.; Zhou, Z.; Xu, C.; Bai, L.; Wang, X.; Han, L.; Zhang, Q.; Li, G. Study on the Synergistic Effects between Petroleum Sulfonate and a Nonionic-Anionic Surfactant for Enhanced Oil Recovery. Energies 2022, 15, 1177. https://doi.org/10.3390/ en15031177

Academic Editor: Rouhi Farajzadeh

Received: 28 December 2021

Accepted: 2 February 2022

Published: 5 February 2022

Publisher's Note: MDPI stays neutral with regard to jurisdictional claims in published maps and institutional affiliations.

Copyright: () 2022 by the authors Licensee MDPI, Basel, Switzerland. This article is an open access article distributed under the terms and conditions of the Creative Commons Attribution (CC BY) license (https:// creativecommons.org/licenses/by/ $4.0 /)$.

\begin{abstract}
Nonionic-anionic surfactants are expected to be applied in chemical flooding due to their important properties such as ultralow IFT values, good salt tolerance, and no chromatographic separation in porous media. In this study, a new type of nonionic-anionic-hydrophobic group structure surfactant N, N-dihydroxyethylalkylamide carboxylate (EAMC) was synthesized. The synergistic effects between petroleum sulfonate (KPS) and EAMC in reducing interfacial tension (IFT) and emulsification properties were studied. The influences of salt, alkali and $\mathrm{Ca}^{2+}$ on the IFTs of surfactant solutions were also investigated. One-dimensional core flooding experiments were used to characterize the enhanced oil recovery capability of the KPS and EAMC mixed system. The experimental results show that both EAMC and KPS have high interfacial activity and can reduce IFTs to about $0.01 \mathrm{mN} / \mathrm{m}$ order of magnitude against decane at optimized concentrations. The area occupied by the hydrophilic group of EAMC on the interface is smaller than that of its own hydrophobic group. The interfacial film formed by EAMC alone is relatively loose. The IFTs of KPS containing different structure petroleum sulfonates is affected by the difference in the adsorption rate of petroleum sulfonates on the interface, which shows that both the dynamic and equilibrium interfacial tensions can have the lowest values. However, the IFTs of the EAMC solutions against crude oil can be reduced to ultralow values because the mixed tight adsorption film is formed by EAMC and crude oil fraction molecules with synergistic effect. On the other hand, the KPS molecule has a hydrophobic part with large size and no synergism with crude oil fractions can be observed in the solutions containing only KPS. The combination of EAMC and KPS shows synergistic effect, namely ultralow IFT values, good emulsification properties, high alkali tolerance, and good salt and $\mathrm{Ca}^{2+}$ tolerance during a wide percentage range of EAMC. The best formula of EAMC and KPS system can be applied for EOR after polymer flooding. The studies in this paper are helpful for the design and application of a chemical flooding formula with nonionic-anionic-hydrophobic group structure surfactants.
\end{abstract}

Keywords: petroleum sulfonate; nonionic-anionic surfactant; synergistic effect; interfacial tension; enhanced oil recovery

\section{Introduction}

After the traditional primary and secondary methods of oil recovery, there are still two-thirds of crude oil left in an oilfield reservoir [1,2]. Therefore, development of tertiary oil recovery methods employing a chemical substance, such as a surfactant, polymer or alkali, to enhance oil recovery (EOR) will be a significant and promising area of work for energy production over the next decades [3]. It has been shown that residual oil trapped 
in a reservoir can be displaced by increasing the capillary number, $N c$, which determines the microscopic displacement efficiency of oil [4,5]. Reduction of the oil/water interfacial tension (IFT) is one of the most effective ways to improve the Nc value. The efficiency of oil recovery would be greatly enhanced if the IFT value between the displacing aqueous and crude oil attained an ultralow value $\left(<10^{-2} \mathrm{mN} / \mathrm{m}\right)$ [6].

In tertiary oil recovery, alkali flooding is an effective way to enhance oil recovery, especially for crude oil reservoirs containing petroleum acids, because the reaction of the alkaline solution with the organic acids in the crude oil and the generation of surfaceactive species, called in-situ surfactant (ionized acid), at the interface result in a remarkable decrease in IFTs [7-10]. However, with the desorption of water-soluble ionized acid from the interface to an aqueous phase the dynamic IFT increases and the equilibrium IFT value becomes higher [11].

The combination of the surfactant and alkali can provide both transient and equilibrium ultralow IFT values [12-14]. Petroleum sulfonate (PS) has been widely used in chemical flooding at oil fields as an EOR surfactant. It possesses the advantages of widely available raw material sources, low prices and good compatibility and emulsion performance. However, the complex composition of PS leads to a narrow concentration range for ultralow IFT values and poor salt resistance, which limits the applications of PS in EOR. Therefore, it is necessary to develop the best formula system when PS is employed as EOR surfactant.

Many researchers have focused on the properties of PS and co-surfactants, with results demonstrating that a complex system can enhance the performance of PS [15-20]. Anionic surfactants with a nonionic hydrophilic group, a so called nonionic-anionic surfactant, such as fatty alcohol polyoxyethylene ether carboxylate (AEC) and sulfonate (AES), are good surfactants that have been widely studied for surface activity, foaming capability, emulsifying properties, wettability change and their performance in decreasing the IFT between oil and water [21-26]. The chemical structure of AEC contains two hydrophilic groups, which enables an ultralow IFT value, and better salt resistance and compatibility than traditional surfactants $[27,28]$. In addition, anionic-nonionic surfactants offer the possibility of obtaining ideal microemulsion-phase behavior for enhanced oil recovery at low surfactant concentrations [29-31]. Moreover, the use of nonionic-anionic surfactants can avoid chromatographic separation due to the different adsorption capacity of non-ion and anion on rock surface [32]. Studies on anionic-nonionic surfactants with such an ionicnonionic-hydrophobic group structure have been extensively reported. However, research and application of nonionic-anionic surfactants with a nonionic-ionic-hydrophobic group structure are relatively rare.

In this paper, a new type of nonionic-anionic-hydrophobic group structure surfactant, $\mathrm{N}, \mathrm{N}$-dihydroxyethylalkylamide carboxylate (EAMC), was synthesized to enhance the performance and application of the PS surfactant in oilfield chemical flooding. The synergistic effects of reducing IFT and emulsifying between nonionic-anionic surfactant EACM and anionic surfactant PS have been studied systematically. The optimal formulation of the nonionic-anionic-hydrophobic group structure surfactant EACM and anionic surfactant PS was applied to one-dimensional oil flooding experiments to verify the enhanced oil recovery effect of the formulation after polymer flooding.

\section{Materials and Methods}

\subsection{Materials}

The anionic surfactant used in this study was petroleum sulfonate (KPS) supplied by JinTa Company of XinJiang, Karamay, China (industrial products, effective content of $40.0 \mathrm{wt} \%$, average molecular weight of 400). KPS is a mixed petroleum sulfonate surfactant obtained from sulfonated vacuum residue. There are a lot of branched, saturated and unsaturated naphthenes on the KPS hydrophobic group. The major component of KPS is benzodicyclohexane sulfonate, with a diversified minority of alkyl benzene sulfonate, alkyl indan sulfonate, alkyl tetrahydronaphthalene sulfonate, alkyl naphthalene 
sulfonate, alkyl acenaphthene sulfonate and alkyl fluorine sulfonate. The nonionic-anionic surfactant was synthesized in our laboratory with purity of more than $90 \mathrm{wt} \%$ as shown in Scheme 1. The purity of the nonionic-anionic surfactant was determined by titration of the carboxylate content. The crude oil sample was provided by the Xinjiang oilfield, Karamay, China. $\mathrm{NaCl}, \mathrm{Na}_{2} \mathrm{CO}_{3}$ and $\mathrm{CaCl}_{2}$ were all analytical grade obtained from Kemiou Company, Tian Jin, China. Polymer HPAM KB2000 was obtained from Hengjv Company, Beijing, China (average molecular weight of $2500 \times 10^{6}$ ). The alkanes with purity of $99+$ $\mathrm{mol} \%$ (GC) were purchased from Aladdin Industrial Corporation, Shanghai, China. The composition of formation water used in the preparation of the aqueous solution is listed in Table 1.

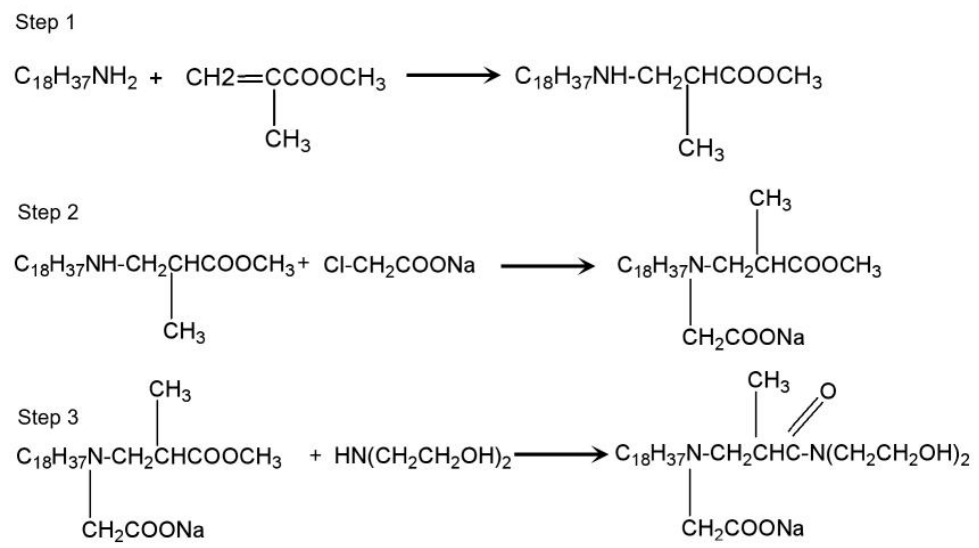

Scheme 1. Synthesis route of surfactant N, N-dihydroxyethylalkylamide carboxylate (EAMC).

Table 1. Composition analysis of the formation brine.

\begin{tabular}{ccccccccc}
\hline Components & TDS & $\mathbf{C a}^{2+}$ & $\mathbf{M g}^{2+}$ & $\mathbf{S O}_{4}{ }^{2-}$ & $\mathbf{C O}_{3}{ }^{2-}$ & $\mathbf{H C O}_{3}{ }^{-}$ & $\mathbf{N a}^{+}$ & $\mathbf{C l}^{-}$ \\
\hline Concentration $/ \mathrm{mg} \cdot \mathrm{L}^{-1}$ & 472.98 & 64.49 & 6.11 & 191.2 & 0 & 98.41 & 70.50 & 42.27 \\
\hline
\end{tabular}

\subsection{Apparatus and Methods}

2.2.1. Interfacial Tension (IFT) Measurements

Dynamic IFTs were measured by the spinning drop technique with a Texas-500C full range tensiometer (Bowing Industry Corporation, Stafford, TX, USA) under standard atmospheric pressure. According to the formation temperature, the experiments were performed at $34.0 \pm 0.1{ }^{\circ} \mathrm{C}$. Various chemical flooding solutions were prepared. Before measurement, the surfactant solutions were placed in a constant temperature bath for $24 \mathrm{~h}$. Petroleum ether, ethanol and the measured solution were used to wash the centrifuge tube sequentially. The surfactant solutions and crude oil were injected into the centrifuge tube appropriately. During the measurement, the rotation speed was maintained at $6000 \mathrm{rpm}$. The volumetric ratio of water to oil in the spinning-drop tensiometer was about 200. IFTs were assumed to be equilibrated when the measured values of IFT remained nearly unchanged for half an hour.

\subsubsection{Emulsification Measurements}

Before use, the crude oil was stored in a refrigerator protected by argon to prevent oxidation. Prior to emulsification, the oil was heated to $34{ }^{\circ} \mathrm{C}$ and shaken to ensure a homogeneous mixture for sampling. Emulsions were made from a volume of oil and a known composition of KPS or EACM system aqueous solution, constantly 1/1 (v/v), a total of $20 \mathrm{~mL}$ placed in a $30 \mathrm{~mL}$ test tube, with an Shaker Loopster digital (IKA, Staufen, Germany) at $35 \mathrm{rpm}$ for $24 \mathrm{~h}$ in a $34{ }^{\circ} \mathrm{C}$ water bath. Then the volume of crude oil emulsion and the volume of water were recorded. 


\subsubsection{Oil Displacement Measurements}

Artificial cores were used in the core flooding oil displacement experiments. The artificial cores used in the experiments were selected according to the permeability of the target reservoir. The cores were saturated with formation water, after which the water was displaced by crude oil until irreducible water saturation was established. After aging for $24 \mathrm{~h}$ at $34.0^{\circ} \mathrm{C}$, the water displacement process began immediately until no oil flowed out at the outlet. Then, the chemical flooding solution was injected, and displacement began again until no oil exited at the outlet. The total oil recovery was then calculated.

\section{Results and Discussion}

\subsection{Interfacial Properties}

\subsubsection{The IFTs of Surfactant Solutions against N-decane}

It is well known that oil and water have opposite polarity. The greater the dissimilarity in their natures is, the greater the IFTs value between them [33]. A surfactant is an amphiphilic molecule that can decrease IFTs between the oil phase and water phase obviously. The reduction of IFT depends on the replacement of molecules of water and oil at the interface by molecules of surfactant. Reaching an ultralow IFT value $\left(<10^{-2} \mathrm{mN} / \mathrm{m}\right)$ demands that the nature of both sides of the interface must be very similar, which means the formation of a tight adsorption film by surfactant molecules with matching sizes of hydrophilic and hydrophobic parts [23].

The dynamic IFTs of KPS and EAMC solutions with different bulk concentrations against decane have been measured and the results are plotted in Figure 1. The effects of concentration on the equilibrium IFTs of KPS and EAMC solutions are shown in Figure 2. It appears, in Figure 1, that the most dynamic IFT curves of KPS and EAMC show the typical shape of " $\mathrm{L}$ ", which means there is a continuous decrease of dynamic IFT to equilibrium value with the gradual diffusing and adsorbing of surfactant molecules from the bulk phase to the interface. However, for the $0.1 \mathrm{wt} \%$ KPS solution (Figure 1a), transient ultralow IFT values appear in a short period of time, and the dynamic IFT curve passes through an obvious minimum. Petroleum sulfonate surfactants with different molecular weights and interfacial activities mixed in KPS have different adsorption rates from bulk to interface. During the dynamic adsorption process, the surfactants that adsorb quickly to the interface preferentially form an interfacial film with lower IFT. However, when the surfactant with a slower adsorption rate further occupies the interfacial film, the arrangement of the surfactant on the interfacial film becomes less dense, which is manifested as an increase in IFT. As shown in Figure 2, the equilibrium IFTs of KPS solutions decrease with increasing concentration firstly and then increase after $0.05 \mathrm{wt} \%$, also indicating that the mixture composition of petroleum sulfonate surfactant KPS had an effect on the interfacial tension. The low-concentration $(<0.05 \mathrm{wt} \%)$ surfactants of KPS are not fully occupied on the interface, so the IFT decreases with the increase of the surfactant concentration. With the further increase of KPS concentration, competitive adsorption appeared on the interface. The slower adsorbing petroleum sulfonate components reach adsorption equilibrium on the interface at an increased rate and occupy a larger proportion of the interface, resulting in an increase in IFTs with increasing surfactant concentration. On the other hand, the equilibrium IFTs of EAMC solutions decrease continuously with increasing concentration. Compared with KPS, EAMC has higher purity and a relatively singular molecular structure, so it shows an ideal equilibrium IFT curve. In addition, even though the EAMC hydrophobic group is a straight alkyl chain (occupying a smaller area at the interface than the KPS hydrophobic group), the IFT minimum value of EAMC is not as low as that of KPD. This indicates that the area occupied by the hydrophilic group of EAMC on the interface is smaller than that of its own hydrophobic group. The interfacial film formed by EAMC with a different interfacial area occupied by hydrophilic and hydrophobic groups is relatively loose, resulting in higher IFTs for EAMC than KPS. It is also worth noting that Figure 2 is on a logarithmic scale, which magnifies the difference in IFTs at 
lower values. Both surfactants show high interfacial activity and can reduce IFTs to about $0.01 \mathrm{mN} / \mathrm{m}$ order of magnitude at optimized concentrations.
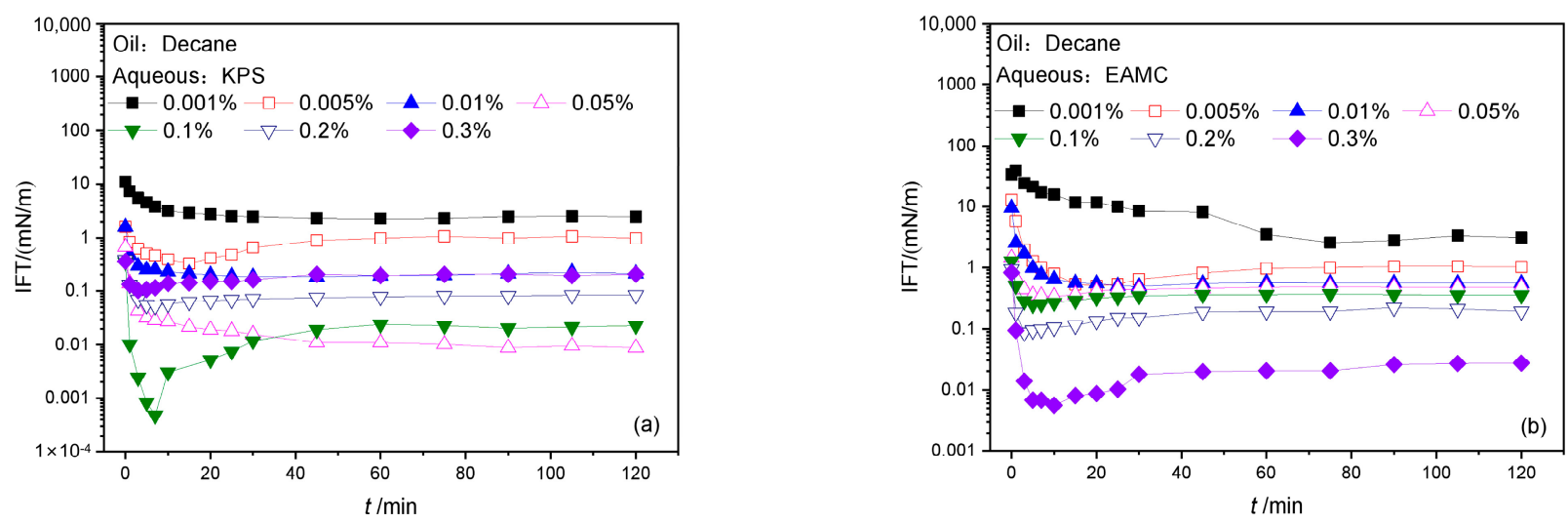

Figure 1. The dynamic IFTs of KPS (a) and EAMC (b) solutions against decane.

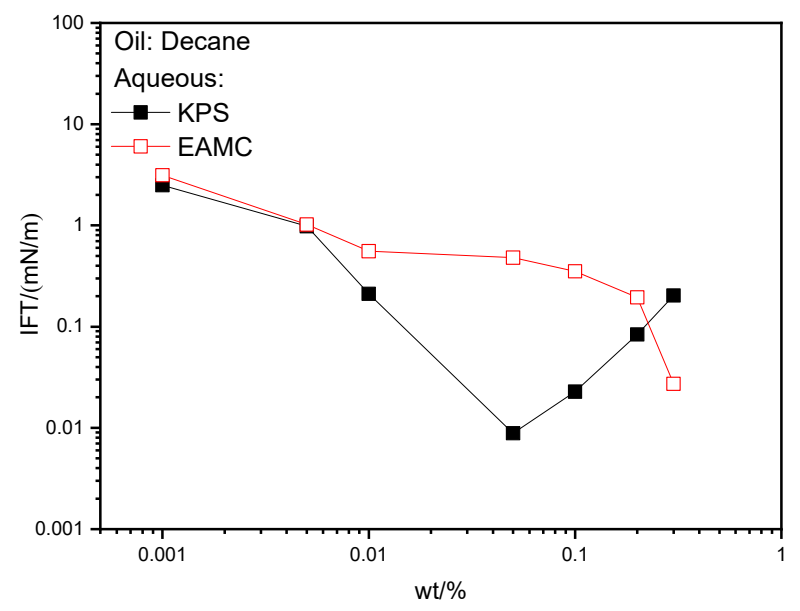

Figure 2. Effect of concentration on the equilibrium IFTs of KPS and EAMC solutions.

\subsubsection{The IFTs of Chemical Flooding Solutions against Crude Oil}

The Salt Tolerance of EAMC and HPAM Solutions

The salt tolerance of $0.3 \mathrm{wt} \%$ EAMC and $0.18 \mathrm{wt} \%$ HPAM solution was investigated and the experimental results are plotted in Figure 3. EAMC exhibits superior salt tolerance due to the presence of $\mathrm{EO}$ nonionic groups in the surfactant. In addition, the equilibrium IFTs with increasing $\mathrm{NaCL}$ due to the compression of the diffusive electric double layer of COO-Na group were simultaneously present in the EAMC surfactant. The ultralow IFT values can be obtained in a wide salinity range from $0.8 \mathrm{wt} \%$ to $5.0 \mathrm{wt} \%$. Moreover, the IFTs of EAMC solutions against crude oil seem to be lower than those against decane, which can be attributed to the formation of a mixed adsorption film by EACM and crude oil fraction molecules.

\section{The Alkali Tolerance of EAMC and HPAM Solutions}

The alkali tolerance of $0.3 \mathrm{wt} \%$ EAMC and $0.18 \mathrm{wt} \%$ HPAM solution was also investigated and the experimental results are plotted in Figure 4. We can see from Figure 4 that ultralow IFT values appear when $\mathrm{Na}_{2} \mathrm{CO}_{3}$ has been added with a concentration range from $0.4 \mathrm{wt} \%$ to $1.4 \mathrm{wt} \%$. This indicates the surface-active substances produced by the reaction of alkali and petroleum acids show synergism with EAMC in reducing IFT. 


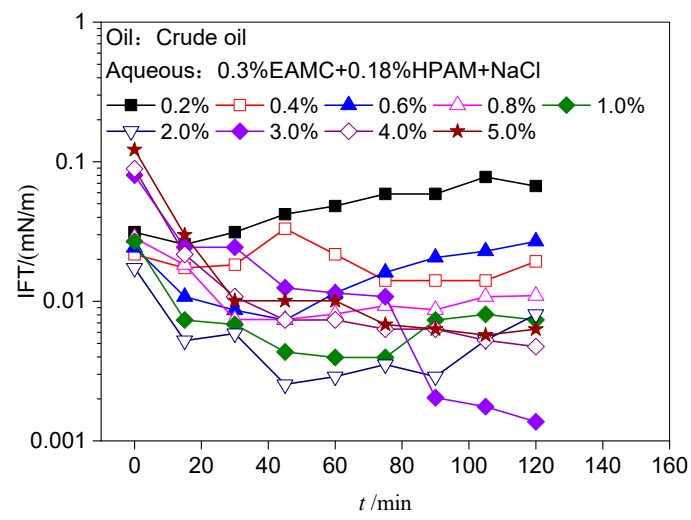

Figure 3. The effect of $\mathrm{NaCl}$ on the dynamic IFTs of EAMC and HPAM solutions. The concentration of $\mathrm{NaCl}$ is represented by lines with different colors and shapes.

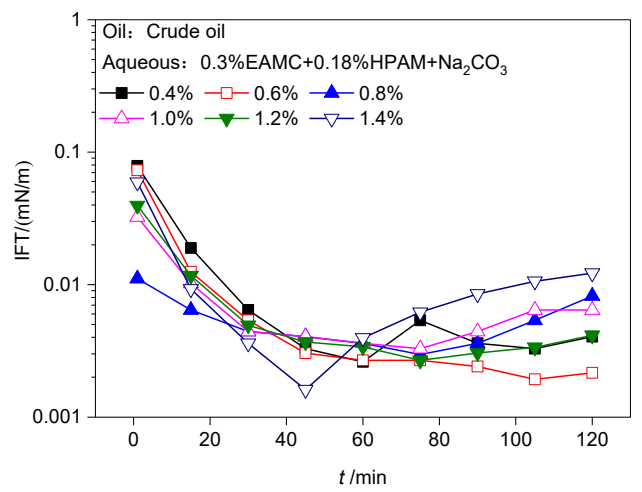

Figure 4. The effect of $\mathrm{Na}_{2} \mathrm{CO}_{3}$ on the dynamic IFTs of EAMC and HPAM solutions.

The Effect of EAMC on the IFTs of KPS and HPAM Solutions

Figure 5 shows the effects of EAMC on the IFTs of KPS and HPAM solutions in a system of the following composition $0.3 \mathrm{wt} \%$ total surfactants, $0.18 \mathrm{wt} \%$ HPAM and $1.2 \mathrm{wt} \% \mathrm{Na}_{2} \mathrm{CO}_{3}$. It must be pointed out that KPS shows lower interfacial active against crude oil than that of EAMC, which comes from the structural difference between KPS and EAMC. EAMC molecule contains two hydrophilic groups (EO groups and carboxylic acid group) and a hydrophobic straight alkyl chain. Therefore, spaces exist at the hydrophobic side of EAMC film and the mixed adsorption of crude oil fraction and EAMC molecules will lead to the tight adsorption film. As a result, IFTs decrease to ultralow values. On the other hand, the petroleum sulfonate molecule has a hydrophobic part with a large size, and no synergism can be observed in the solutions containing only KPS. However, when EAMC has been added to a KPS solution to fill the vacancies of the KPS interface film, even 10 percent of EAMC can reduce the IFT of KPS to an ultralow value.

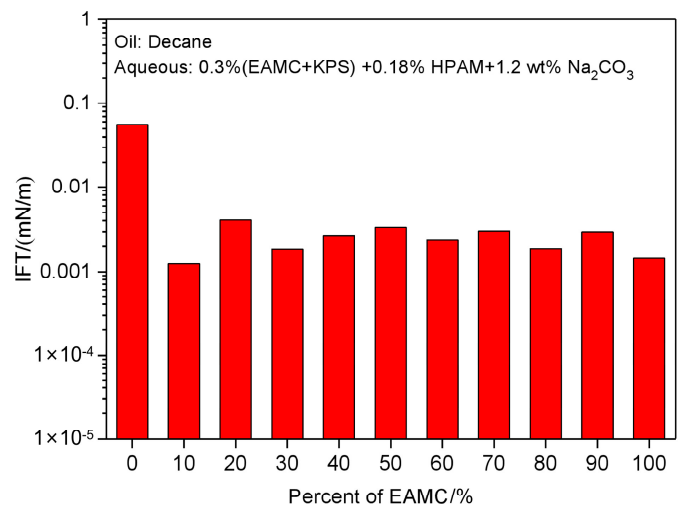

Figure 5. The effect of the percentage of EAMC on the IFTs of KPS and HPAM solutions. 
The Alkali Tolerance of KPS and EAMC, and HPAM Solutions

Based on the experimental results and surfactant economic costs, the following formula was selected: $0.3 \mathrm{wt} \%$ surfactants (KPS: EAMC, 8:2), $0.18 \mathrm{wt} \% \mathrm{HPAM}$ and $\mathrm{Na}_{2} \mathrm{CO}_{3}$. Figure 6 shows the effects of the alkali concentration on the dynamic IFTs. The IFT of formula system decreases by $10^{-3} \mathrm{mN} / \mathrm{m}$ order of magnitude when the alkali concentration increases. The preferable alkali concentration range of $\mathrm{Na}_{2} \mathrm{CO}_{3}$ is from $0.6 \mathrm{wt} \%$ to $1.4 \mathrm{wt} \%$ and the optimal $\mathrm{Na}_{2} \mathrm{CO}_{3}$ concentration is $1.2 \mathrm{wt} \%$.

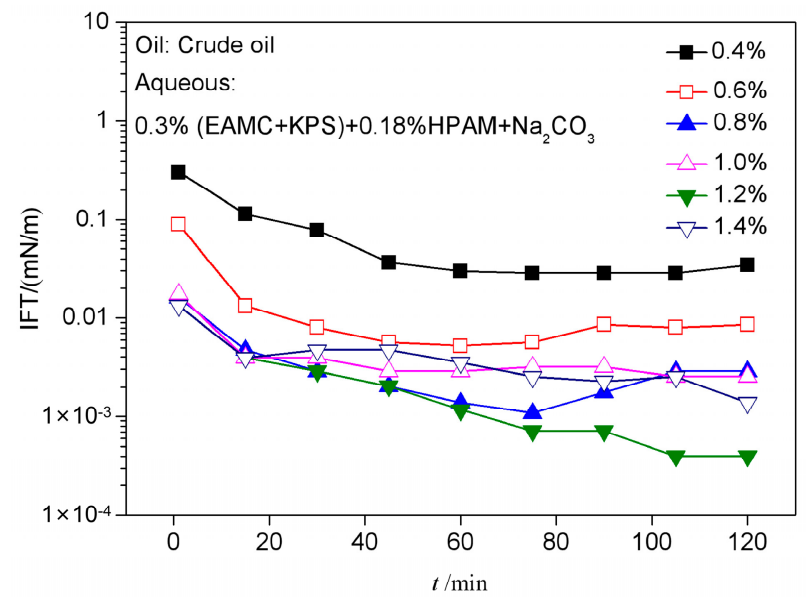

Figure 6. The effect of $\mathrm{Na}_{2} \mathrm{CO}_{3}$ on the dynamic IFTs of KPS and EAMC, and HPAM solutions.

The Effect of $\mathrm{Ca}^{2+}$ on the Dynamic IFTs of Chemical Flooding Solutions

The effect of $\mathrm{Ca}^{2+}$ concentration on the IFTs of $0.3 \mathrm{wt} \%$ (KPS: EAMC, 8:2) $+0.18 \mathrm{wt} \%$ $\mathrm{HPAM}+1.2 \mathrm{wt} \% \mathrm{Na}_{2} \mathrm{CO}_{3}$ solution has been studied and the experimental results are plotted in Figure 7. As the $\mathrm{Ca}^{2+}$ concentration increases from $100 \mathrm{mg} / \mathrm{L}$ to $300 \mathrm{mg} / \mathrm{L}$, the IFT decreases to $10^{-3} \mathrm{mN} / \mathrm{m}$. Then the IFT increases to $10^{-2} \mathrm{mN} / \mathrm{m}$ when the $\mathrm{Ca}^{2+}$ concentration further increases from $400 \mathrm{mg} / \mathrm{L}$ to $800 \mathrm{mg} / \mathrm{L}$. The reasons for this result are that if extra $\mathrm{Ca}^{2+}$ is added into the surfactant solution, it can compress the diffusion electric double layers of the sulfonic acid group of KPS and the carboxylic acid group of EAMC, and the surfactants could aggregate closely at the interface. As a result, IFT decreases. However, when the $\mathrm{Ca}^{2+}$ concentration is above $400 \mathrm{~g} / \mathrm{L}$, the hydrophilicity of the ionic groups of KPS and EAMC is further reduced, and the surfactants at the interface are no longer in their most tightly packed state. Therefore, IFT increases.

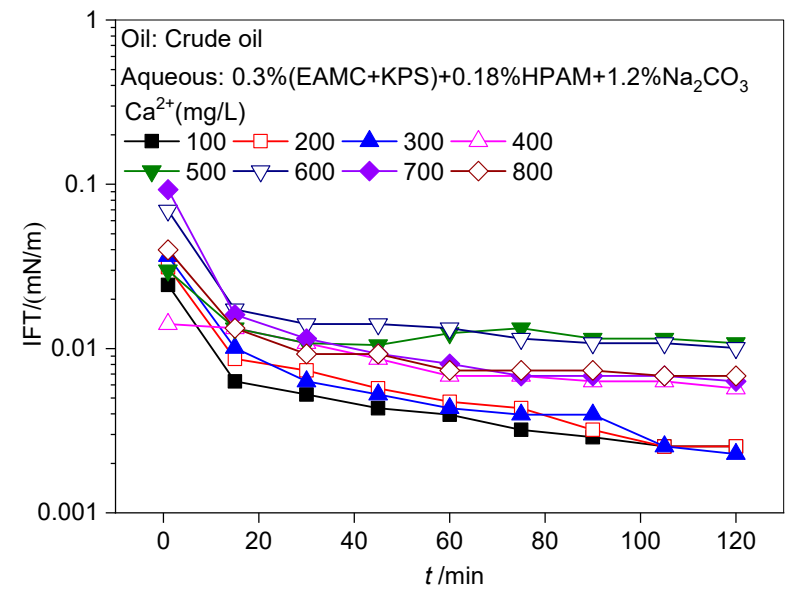

Figure 7. The effect of $\mathrm{Ca}^{2+}$ on the dynamic IFTs of chemical flooding solutions. 


\subsection{Emulsification Properties}

\subsubsection{Effect of Alkali Concentration}

The effect of $\mathrm{Na}_{2} \mathrm{CO}_{3}$ concentration on the emulsification properties of $0.3 \mathrm{wt} \%$ (KPS: EAMC, 8:2) solution were investigated, as shown in Figure 8. With the increase in alkali concentration, both the oil emulsification rate and the moisture content of the emulsion increase slightly to a plateau. The preferable $\mathrm{Na}_{2} \mathrm{CO}_{3}$ concentration range is from $0.8 \mathrm{wt} \%$ to $1.4 \mathrm{wt} \%$. There is a significant correlation between emulsification rate and interfacial tension. The addition of alkali not only compresses the electric double layer of the ionic groups of KPS and EAMC, but also reacts with the active components in crude oil to form petroleum acid soap. These two actions make the interfacial film of the surfactant tighter, which means lower interfacial tension. When a certain energy is input to emulsify the solution, the lower the interfacial tension is, the larger the oil-water interface area (i.e., the emulsification rate) is.

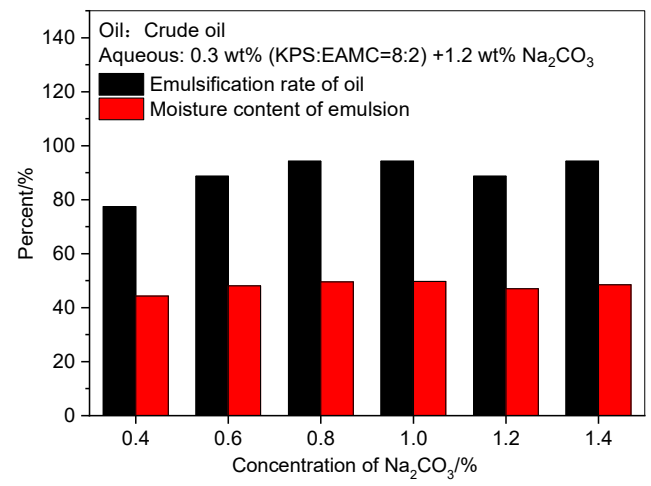

Figure 8. The effect of $\mathrm{Na}_{2} \mathrm{CO}_{3}$ on the emulsification properties of KPS and EAMC solution.

\subsubsection{Effect of Mixed Surfactant Ratio}

To keep the total surfactant concentration of 0.3 wt \% and $\mathrm{Na}_{2} \mathrm{CO}_{3}$ concentration of $1.2 \mathrm{wt} \%$ respectively, the effect of the EAMC ratio on the emulsification properties of chemical flooding solution was studied and the experimental results are plotted in Figure 9. As the EAMC ratio varies from 5\% to 95\%, the chemical flooding solutions all show good emulsification properties and both the oil emulsification rate and the content of the emulsion change little. When the content of either EAMC or KPS in the mixed solution of EAMC and KPS surfactants is very small, the ability of EAMC and KPS to synergistically generate a new oil-water interface is weakened, resulting in a relatively low emulsification rate, as shown in Figure 9.

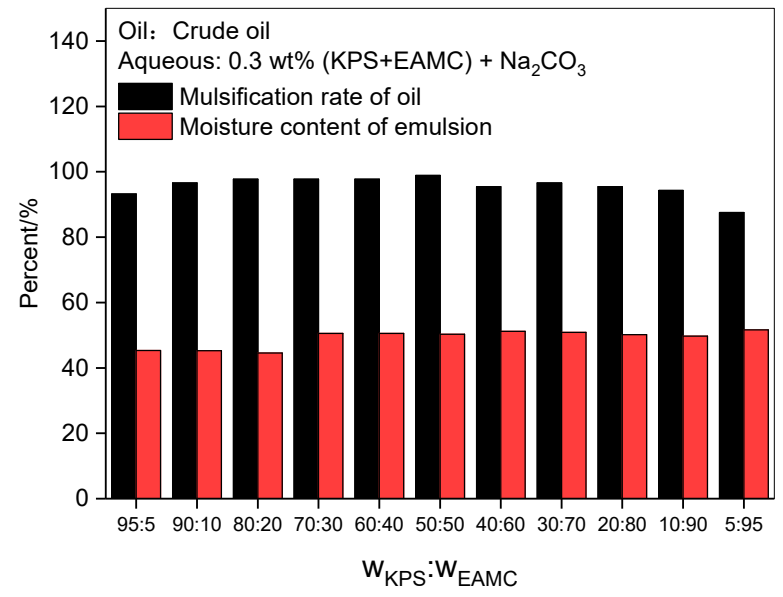

Figure 9. The effect of a mixed surfactant ratio on the emulsification properties. 


\subsection{Oil Displacement Test}

\subsubsection{ASP Flooding}

Oil displacement tests of EAMC and KPS systems were conducted. Table 2 and Figure 10 show that the EOR of ASP flooding is $12.56 \%$, which is lower than normal ASP flooding. During the entire chemical flooding experiment, the water phase of the core-produced fluid remained clear and transparent. No Tyndall effect of emulsions or colloids was observed with the naked eye in the produced fluids. The injection pressure of ASP flooding in Figure 10 is lower than that of polymer flooding in Figure 11, which proves that the ASP system emulsifies and produces an oil washing effect, which causes the ASP system to expand the flow channel of the aqueous solution and reduce the injection pressure. The absence of emulsion at the outlet indicates that the emulsion was retained in the porous medium and did not migrate out of the core. This experimental result shows that the longitudinal sweep volume of the system needs to be further improved.

Table 2. Experiment of ASP flooding after water flooding.

\begin{tabular}{cccc}
\hline Section & Data & Section & Data \\
\hline Diameter $/ \mathrm{cm}$ & 3.8 & Product well number & T71748 \\
Porosity $/ \mathrm{wt} \%$ & 14.33 & Length $/ \mathrm{cm}$ & 29.3 \\
$\mathrm{~K}_{\mathrm{air}} / \mu \mathrm{m}^{2}$ & 0.57802 & Pore volume $/ \mathrm{mL}$ & 55.6 \\
$\mathrm{~K}_{\mathrm{oil}} / \mu \mathrm{m}^{2}$ & 0.83 & $\mathrm{~K}_{\mathrm{water}} / \mu \mathrm{m}^{2}$ & 50.0 \\
$\mathrm{~T}$ & $\mathrm{~S}_{\mathrm{oi}} / \mathrm{mL}$ & 44.6 \\
$\mathrm{~T} /{ }^{\circ} \mathrm{C}$ & 34 & Injection flow $/ \mathrm{mL} / \mathrm{min}$ & 0.5 \\
$\mathrm{IFT} / \mathrm{mN} \cdot \mathrm{m}^{-1}$ & 0.0059 & Oil recovery by water flooding $/ \%$ & 41.64 \\
Total Oil recovery $/ \%$ & 54.20 & Oil recovery by ASP flooding $/ \%$ & 12.56 \\
\hline
\end{tabular}

Formula system: $0.18 \mathrm{wt} \%$ polymer (KB2000) $+0.3 \mathrm{wt} \%$ surfactant (KPS: EAMC, 8:2) $+1.2 \mathrm{wt} \% \mathrm{Na}_{2} \mathrm{CO}_{3}$.

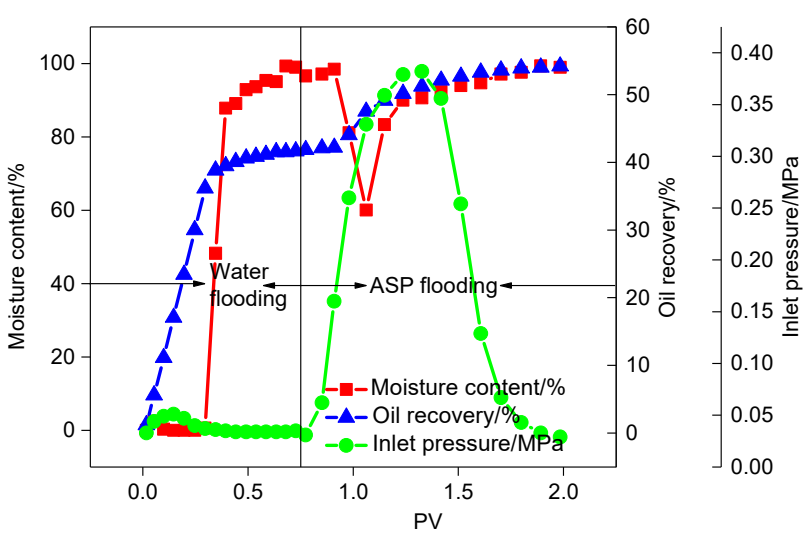

Figure 10. Curves of the injection and production of ASP flooding.

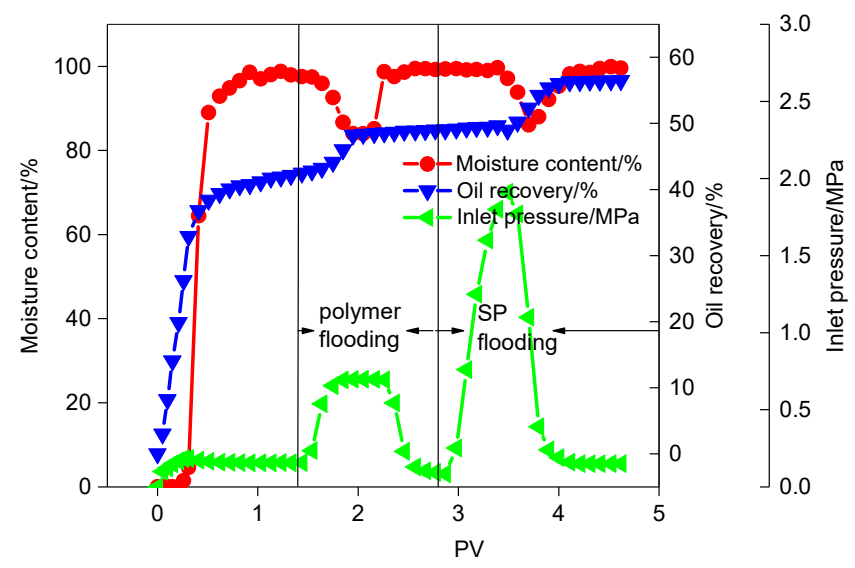

Figure 11. Curves of the injection and production of SP flooding after polymer flooding. 


\subsubsection{SP Flooding after Polymer Flooding}

Table 3 and Figure 11 show that the SP formula system showed good performance in enhancing oil recovery after the polymer flooding. The EOR of polymer flooding and SP flooding were $7.05 \%$ and $7.57 \%$, respectively. The total EOR of polymer flooding plus SP flooding was $14.62 \%$, higher than that of single ASP slug flooding in Figure 10, which shows that the optimal SP formula system is suitable for the process after polymer flooding of EOR.

Table 3. Experiment of SP flooding after polymer flooding.

\begin{tabular}{cccc}
\hline Section & Data & Section & Data \\
\hline Diameter $/ \mathrm{cm}$ & 3.8 & Product well number & ES7013 \\
Porosity $/ \%$ & 14.32 & Length $/ \mathrm{cm}$ & 30 \\
$\mathrm{~K}_{\mathrm{air}} / \mu^{2}$ & Pore volume $/ \mathrm{mL}$ & 48.7 \\
$\mathrm{~K}_{\mathrm{oil}} / \mu^{2}$ & $\mathrm{~K}_{\mathrm{water}} / \mathrm{\mu m}^{2}$ & 0.52 \\
$\mathrm{~T} /{ }^{\circ} \mathrm{C}$ & 0.5703 & $\mathrm{~S}_{\mathrm{oi}} / \mathrm{mL}$ & 36.2 \\
Crude oil viscosity $/ \mathrm{mPa} . \mathrm{s}$ & 20.81 & Injection flow $/ \mathrm{mL} / \mathrm{min}$ & 0.5 \\
Oil recovery by polymer flooding $/ \%$ & 7.05 & Oil recovery by water flooding $/ \%$ & 41.88 \\
$\mathrm{EOR} / \%$ & 14.62 & Oil recovery by SP flooding $/ \%$ & 7.57 \\
$\mathrm{IFT} / \mathrm{mN} \cdot \mathrm{m}^{-1}$ & 0.00462 & Total oil recovery $/ \%$ & 56.49 \\
\hline
\end{tabular}

Formula system: slug 1: $0.1 \mathrm{wt} \%$ polymer (KB2000(0.7 PV)); slug 2: $0.2 \mathrm{wt} \%$ polymer (KB2000)+ 0.3 wt \% (KPS:EAMC, 8:2).

\subsubsection{ASP Flooding after Polymer Flooding}

Table 4 and Figure 12 show that the ASP formula system also showed good performance in enhancing oil recovery after the polymer flooding. The EOR of polymer flooding and SP flooding were $7.71 \%$ and $9.78 \%$, respectively. The total EOR of chemical flooding was $17.49 \%$, which shows that the optimal ASP formula system is more suitable for the enhanced oil recovery process after polymer flooding than the SP formulation.

Table 4. Experiment of ASP flooding after polymer flooding.

\begin{tabular}{|c|c|c|c|}
\hline Section & Data & Section & Data \\
\hline Diameter $/ \mathrm{cm}$ & 3.8 & Product well number & ES7013 \\
\hline Porosity /\% & 14.06 & Length $/ \mathrm{cm}$ & 30 \\
\hline $\mathrm{K}_{\mathrm{air}} / \mu \mathrm{m}^{2}$ & 0.5800 & Pore volume $/ \mathrm{mL}$ & 47.8 \\
\hline $\mathrm{K}_{\mathrm{oil}} / \mu \mathrm{m}^{2}$ & 0.831 & $\mathrm{~K}_{\text {water }} / \mu \mathrm{m}^{2}$ & 0.53 \\
\hline Crude oil viscosity /mPa.s & 20.81 & $\mathrm{~S}_{\mathrm{oi}} / \mathrm{mL}$ & 35.9 \\
\hline $\mathrm{T} /{ }^{\circ} \mathrm{C}$ & 34.3 & Injection flow $/ \mathrm{mL} \cdot \mathrm{min}^{-1}$ & 0.50 \\
\hline Oil recovery by polymer flooding/\% & 7.71 & Oil recovery by water flooding / \% & 38.89 \\
\hline EOR $/ \%$ & 17.49 & Oil recovery by ASP flooding/\% & 9.78 \\
\hline $\mathrm{IFT} / \mathrm{mN} \cdot \mathrm{m}^{-1}$ & 0.00462 & Total oil recovery $/ \%$ & 56.38 \\
\hline
\end{tabular}

Formula system: slug 1: $0.1 \mathrm{wt} \%$ polymer (KB2000(0.7 PV)); slug 2: $0.2 \mathrm{wt} \%$ polymer (KB2000) $+0.3 \mathrm{wt} \%$ (KPS: EAMC, 8:2) + 1.2 wt \% $\mathrm{Na}_{2} \mathrm{CO}_{3}(0.5 \mathrm{PV})$.

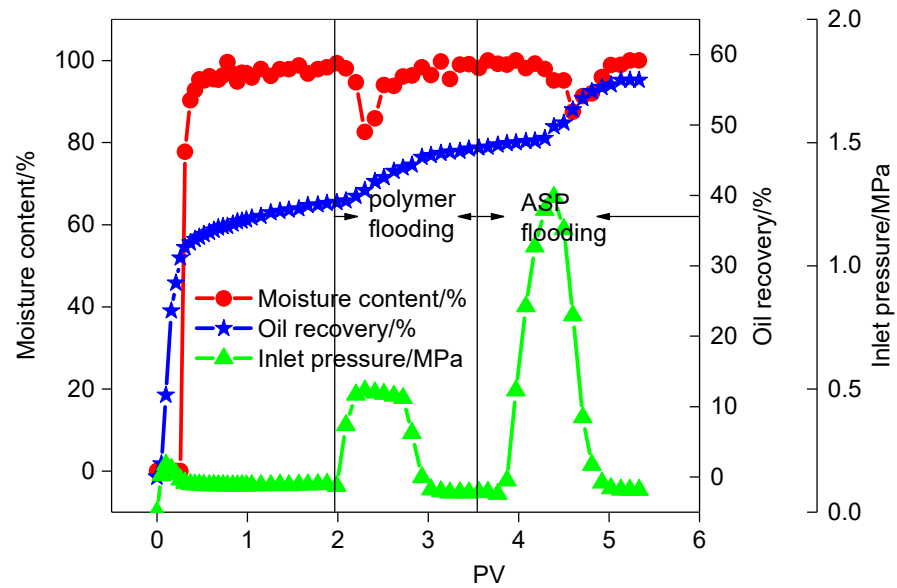

Figure 12. Curves of the injection and production of ASP flooding after polymer flooding. 


\section{Conclusions}

In this study, a new type of nonionic-anionic surfactant (EAMC) was synthesized and the synergistic effects between petroleum sulfonate (KPS) and EAMC for reducing IFT and emulsifying were studied. The EOR effect of the optimal formulation of EACM and KPS was verified. Based on the experimental results, the following conclusions can be drawn:

1. Both EAMC and KPS show high interfacial activity and can reduce IFTs to about $0.01 \mathrm{mN} / \mathrm{m}$ order of magnitude against decane at optimized concentrations.

2. The area occupied by the hydrophilic group of EAMC on the interface is smaller than that of its own hydrophobic group. The interfacial film formed by EAMC is relatively loose. The IFTs of KPS containing different structure petroleum sulfonates is affected by the difference in the adsorption rate of petroleum sulfonates to the interface, which shows that both the dynamic and equilibrium interfacial tensions may have the lowest values.

3. The IFTs of EAMC solutions against crude oil can be reduced to ultralow values because the mixed tight adsorption film will be formed by EAMC and crude oil fraction molecules. On the other hand, the KPS molecule has a hydrophobic part with a large size, and no synergism with crude oil fractions can be observed in the solutions containing only KPS.

4. When EAMC has been added to a KPS solution to fill the vacancies of the KPS interface film, even 10 percent of EAMC can reduce the IFT of KPS to an ultralow value. The combination of EAMC and KPS shows ultralow IFT values, good emulsification properties, high alkali tolerance and good salt and $\mathrm{Ca}^{2+}$ tolerance during a wide range of EAMC percent.

5. The best formula of a EAMC and KPS system can be applied for EOR after polymer flooding. The total EOR value of polymer flooding and following SP flooding is $14.62 \%$. The total EOR value of polymer flooding and following ASP flooding is $17.49 \%$.

The studies in this paper are helpful for the design and application of a chemical flooding formula with nonionic-anionic-hydrophobic group structure surfactants. In future work, it will be necessary to continue to study the arrangement of nonionic-anionic surfactants and petroleum sulfonate on the interface by means of interfacial expansion rheology. In addition, the research on the effect of the ratio of nonionic-anionic surfactant and petroleum sulfonate on the emulsion phase behavior and EOR effect also needs further research.

Author Contributions: Conceptualization, H.L., Z.Z. and G.L.; investigation, C.X. and L.B.; resources, X.W.; experiment, L.H.; data curation, Q.Z.; writing-review and editing, H.L., Z.Z. and G.L.; funding acquisition, H.L. All authors have read and agreed to the published version of the manuscript.

Funding: This research was funded by the China Postdoctoral Science Foundation (2015M572628) and the National Science \& Technology Major Project (2016ZX05011-003) of China.

Conflicts of Interest: The authors declare no conflict of interest.

\section{References}

1. Atilhan, M.; Aparicio, S. Review on Chemical Enhanced Oil Recovery: Utilization of Ionic Liquids and Deep Eutectic Solvents. J. Pet. Sci. Eng. 2021, 205, 108746. [CrossRef]

2. Olajire, A.A. Review of ASP EOR (Alkaline Surfactant Polymer Enhanced Oil Recovery) Technology in the Petroleum Industry: Prospects and Challenges. Energy 2014, 77, 963-982. [CrossRef]

3. Cayias, J.L.; Schechter, R.S.; Wade, W.H. Modeling Crude Oils for Low Interfacial Tension. Soc. Pet. Eng. J. 1976, 16, $351-357$. [CrossRef]

4. Cash, L.; Cayias, J.L.; Fournier, G.; Macallister, D.; Schares, T.; Schechter, R.S.; Wade, W.H. The Application of Low Interfacial Tension Scaling Rules to Binary Hydrocarbon Mixtures. J. Colloid Interface Sci. 1977, 59, 39-44. [CrossRef]

5. Chan, K.S.; Shah, D.O. The Molecular Mechanism for Achieving Ultra Low Interfacial Tension Minimum in a Petroleum Sulfonate/Oil/Brine System. J. Dispers. Sci. Technol. 1980, 1, 55-95. [CrossRef]

6. Deng, X.; Tariq, Z.; Murtaza, M.; Patil, S.; Mahmoud, M.; Kamal, M.S. Relative Contribution of Wettability Alteration and Interfacial Tension Reduction in EOR: A Critical Review. J. Mol. Liq. 2021, 325, 115175. [CrossRef] 
7. Acevedo, S.; Ranaudo, M.A.; Escobar, G.; Gutiérrez, X. Dynamic Interfacial Tension Measurement of Heavy Crude Oil-Alkaline Systems: The Role of the Counterion in the Aqueous Phase. Fuel 1999, 78, 309-317. [CrossRef]

8. Zhao, Z.; Liu, F.; Qiao, W.; Li, Z.; Cheng, L. Novel Alkyl Methylnaphthalene Sulfonate Surfactants: A Good Candidate for Enhanced Oil Recovery. Fuel 2006, 85, 1815-1820. [CrossRef]

9. Sharma, H.; Dufour, S.; Arachchilage, G.W.P.P.; Weerasooriya, U.; Pope, G.A.; Mohanty, K. Alternative Alkalis for ASP Flooding in Anhydrite Containing Oil Reservoirs. Fuel 2015, 140, 407-420. [CrossRef]

10. Alvarado, V.; Manrique, E. Enhanced Oil Recovery: An Update Review. Energies 2010, 3, 1529-1575. [CrossRef]

11. Touhami, Y.; Hornof, V.; Neale, G.H. Dynamic Interfacial Tension Behavior of Acidified Oil/Surfactant-Enhanced Alkaline Systems 1. Experimental Studies. Colloids Surf. A Physicochem. Eng. Asp. 1998, 132, 61-74. [CrossRef]

12. Zhang, L.; Luo, L.; Zhao, S.; Xu, Z.; An, J.; Yu, J. Effect of Different Acidic Fractions in Crude Oil on Dynamic Interfacial Tensions in Surfactant/Alkali/Model Oil Systems. J. Pet. Sci. Eng. 2004, 41, 189-198. [CrossRef]

13. Nowrouzi, I.; Mohammadi, A.H.; Manshad, A.K. Characterization and Evaluation of a Natural Surfactant Extracted from Soapwort Plant for Alkali-Surfactant-Polymer (ASP) Slug Injection into Sandstone Oil Reservoirs. J. Mol. Liq. 2020, 318 , 114369. [CrossRef]

14. Zhao, R.; Huang, H.; Wang, H.; Zhang, J.; Zhang, L.; Zhang, L.; Zhao, S. Effect of Organic Additives and Crude Oil Fractions on Interfacial Tensions of Alkylbenzene Sulfonates. J. Dispers. Sci. Technol. 2013, 34, 623-631. [CrossRef]

15. Aoudia, M.; Al-Shibli, M.N.; Al-Kasimi, L.H.; Al-Maamari, R.; Al-bemani, A. Novel Surfactants for Ultralow Interfacial Tension in a Wide Range of Surfactant Concentration and Temperature. J. Surfact. Deterg. 2006, 9, 287-293. [CrossRef]

16. Zhao, Z.; Bi, C.; Qiao, W.; Li, Z.; Cheng, L. Dynamic Interfacial Tension Behavior of the Novel Surfactant Solutions and Daqing Crude Oil. Colloids Surf. A Physicochem. Eng. Asp. 2007, 294, 191-202. [CrossRef]

17. Li, G.; Wang, K.; Lu, C. Effect of Particle Aggregates on the Surface Properties of Amphiphilic SiO2 Particles in Anhydrous Foam. Chem. J. Chin. Univ.-Chin. 2020, 41, 2038-2045. [CrossRef]

18. Rosen, M.J.; Zhou, Q. Surfactant-Surfactant Interactions in Mixed Monolayer and Mixed Micelle Formation. Langmuir 2001, 17, 3532-3537. [CrossRef]

19. Wang, K.; Li, G.; Zhang, B. Opposite Results of Emulsion Stability Evaluated by the TSI and the Phase Separation Proportion. Colloids Surf. A Physicochem. Eng. Asp. 2018, 558, 402-409. [CrossRef]

20. Bergström, M.; Eriksson, J.C. A Theoretical Analysis of Synergistic Effects in Mixed Surfactant Systems. Langmuir 2000, 16, 7173-7181. [CrossRef]

21. Witthayapanyanon, A.; Acosta, E.J.; Harwell, J.H.; Sabatini, D.A. Formulation of Ultralow Interfacial Tension Systems Using Extended Surfactants. J. Surfact. Deterg. 2006, 9, 331-339. [CrossRef]

22. Aoudia, M.; Al-Maamari, R.S.; Nabipour, M.; Al-Bemani, A.S.; Ayatollahi, S. Laboratory Study of Alkyl Ether Sulfonates for Improved Oil Recovery in High-Salinity Carbonate Reservoirs: A Case Study. Energy Fuels 2010, 24, 3655-3660. [CrossRef]

23. Liu, Z.-Y.; Li, Z.-Q.; Song, X.-W.; Zhang, J.-C.; Zhang, L.; Zhang, L.; Zhao, S. Dynamic Interfacial Tensions of Binary NonionicAnionic and Nonionic Surfactant Mixtures at Water-Alkane Interfaces. Fuel 2014, 135, 91-98. [CrossRef]

24. Al-Sabagh, A.M.; Azzam, E.M.S.; Mahmoud, S.A.; Saleh, N.E.A. Synthesis of Ethoxylated Alkyl Sulfosuccinate Surfactants and the Investigation of Mixed Solutions. J. Surfact. Deterg. 2007, 10, 3-8. [CrossRef]

25. Moslemizadeh, A.; Khayati, H.; Madani, M.; Ghasemi, M.; Shahbazi, K.; Zendehboudi, S.; Hashim Abbas, A. A Systematic Study to Assess Displacement Performance of a Naturally-Derived Surfactant in Flow Porous Systems. Energies 2021, 14, 8310. [CrossRef]

26. Rezaei, A.; Riazi, M.; Escrochi, M.; Elhaei, R. Integrating Surfactant, Alkali and Nano-Fluid Flooding for Enhanced Oil Recovery: A Mechanistic Experimental Study of Novel Chemical Combinations. J. Mol. Liq. 2020, 308, 113106. [CrossRef]

27. Sha, O.; Zhang, W.; Lu, R. Synthesis and Properties Evaluation of Nonionic-Anionic Surfactants Suitable for Enhanced Oil Recovery Using Sea Water. Tenside Surfactants Deterg. 2008, 45, 82-86. [CrossRef]

28. Liu, Z.; Zhang, L.; Cao, X.; Song, X.; Jin, Z.; Zhang, L.; Zhao, S. Effect of Electrolytes on Interfacial Tensions of Alkyl Ether Carboxylate Solutions. Energy Fuels 2013, 27, 3122-3129. [CrossRef]

29. Salager, J.-L.; Forgiarini, A.M.; Bullón, J. How to Attain Ultralow Interfacial Tension and Three-Phase Behavior with Surfactant Formulation for Enhanced Oil Recovery: A Review. Part 1. Optimum Formulation for Simple Surfactant-Oil-Water Ternary Systems. J. Surfactants Deterg. 2013, 16, 449-472. [CrossRef]

30. Goodarzi, F.; Zendehboudi, S. Effects of Salt and Surfactant on Interfacial Characteristics of Water/Oil Systems: Molecular Dynamic Simulations and Dissipative Particle Dynamics. Ind. Eng. Chem. Res. 2019, 58, 8817-8834. [CrossRef]

31. Riswati, S.S.; Bae, W.; Park, C.; Permadi, A.K.; Efriza, I.; Min, B. Experimental Analysis to Design Optimum Phase Type and Salinity Gradient of Alkaline Surfactant Polymer Flooding at Low Saline Reservoir. J. Pet. Sci. Eng. 2019, 173, 1005-1019. [CrossRef]

32. Massarweh, O.; Abushaikha, A.S. The Use of Surfactants in Enhanced Oil Recovery: A Review of Recent Advances. Energy Rep. 2020, 6, 3150-3178. [CrossRef]

33. Rosen, M.J. Surfactants and Interfacial Phenomena, 3rd ed.; Wiley-Interscience: Hoboken, NJ, USA, 2004; ISBN 978-0-471-47818-8. 